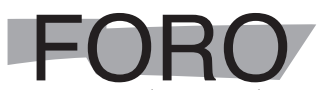

Revista de Derecho

\title{
La fuerza vinculante de las Opiniones Consultivas de la Corte Interamericana de Derechos Humanos a la luz del derecho y la justicia constitucional en Ecuador
}

The binding character of the Inter-American Court of Human Rights Advisory Opinions in light of Ecuadorian constitutional law

Daniela Salazar Marín

Universidad San Francisco de Quito, Ecuador dsalazar@usfq.edu.ec

ORCID: 0000-0001-9225-4822

\section{Ana Isabel Cobo Ordóñez}

Universidad San Francisco de Quito, Ecuador acoboo@estud.usfa.edu.ec

ORCID: 0000-0001-7305-7305

\section{Camila Cruz García}

Universidad San Francisco de Quito, Ecuador ccruzg@estud.usfq.edu.ec

ORCID: 0000-0002-3249-3925

Mateo Guevara Ruales

Universidad San Francisco de Quito, Ecuador mguevarar@estud.usfq.edu.ec

ORCID: 0000-0002-4313-9681

\section{María Paula Mesías Vela}

Universidad San Francisco de Quito, Ecuador mmesiasv@estud.usfq.edu.ec

ORCID: 0000-0001-9733-4506

DOI: https://doi.org/10.32719/26312484.2019.32.7

Fecha de recepción: 23 de octubre de 2018

Fecha de aceptación: 26 de septiembre de 2019

Licencia Creative Commons

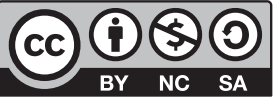




\section{RESUMEN}

La obligatoriedad de las Opiniones Consultivas de la Corte Interamericana de Derechos Humanos se sostiene en los principios rectores del Derecho Internacional Público y las normas de interpretación de los tratados internacionales. Cuando se ratifica un tratado y el órgano encargado de su supervisión emite una interpretación autorizada, los Estados Parte deben cumplir de buena fe con esta interpretación. Durante estos años, el cuestionamiento de la obligatoriedad de las Opiniones Consultivas ha tenido un largo debate doctrinario en los distintos países de Latinoamérica. El objetivo principal de este trabajo es aportar argumentos para reforzar la obligación que tienen los jueces de aplicar los estándares contenidos en la Opinión Consultiva 24/17, realizando el respectivo control de convencionalidad de sus decisiones y tomando en cuenta que los tratados e instrumentos internacionales de derechos humanos forman parte del ordenamiento jurídico a través del bloque de constitucionalidad, como ha sido reconocido por la Corte Constitucional en sus diversas sentencias. Sostenemos que la tarea de los jueces no puede limitarse a observar normas expresas contenidas en textos constitucionales e infraconstitucionales, sino que debe abarcar un control de convencionalidad que garantice el efectivo goce $y$ ejercicio de los derechos fundamentales de toda persona.

Palabras clave: OC-24/17, Constitución, Corte IDH, obligatoriedad, bloque de constitucionalidad, competencia consultiva.

\section{ABSTRACT}

The enforceability of the Advisory Opinions of the Inter-American Court of Human Rights rests on the basic principles of International Public Law and the law of interpretation of treaties. When a treaty is ratifies and the institution entrusted with its supervision issues an authorized interpretation, the States Parties must comply with this interpretation in good faith. In the past years, the mandatory nature of the Advisory Opinions has been questioned through a long doctrinal debate in the different countries of Latin America. The main objective of this paper is to contribute with arguments to reinforce the obligation of judges to apply the standards contained in the Advisory Opinion 24/17, performing a "control of conventionality" of their decisions and taking into account that international human rights treaties and instruments are part of the legal system through the "constitutionality block", as has been recognized by the Constitutional Court in various decisions. We argue that the task of the judges cannot be limited to observe express norms contained in constitutional and infra-constitutional texts, rather, a conventionality control must be carried out in order to guarantee the effective enjoyment and exercise of the fundamental rights of every person.

KeYwords: Advisory Opinion (AO-24/17), Constitution, Inter-American Court of Human Rights, enforceability, "constitutional block", advisory jurisdiction. 


\section{INTRODUCCIÓN*}

T a relación entre el Derecho Internacional de los Derechos Humanos (en adelante DIDH) y el Derecho constitucional interno es una cuestión que ha generado intensos debates en la doctrina y la jurisprudencia. La Constitución de la República del Ecuador (en adelante Constitución) expresamente incorpora a su texto los instrumentos internacionales otorgándoles una jerarquía superior, incluso a la de la propia Constitución, si sus normas son más favorables para el ejercicio de los derechos humanos. Así, la Constitución otorga un valor privilegiado a instrumentos que, no siendo estrictamente tratados internacionales, juegan un rol trascendental en la protección de los derechos de las personas.

El artículo 64 de la Convención Americana sobre Derechos Humanos (en adelante $\mathrm{CADH}$ ) faculta a la Corte Interamericana de Derechos Humanos (en adelante Corte IDH) a recibir consultas acerca de la interpretación de las normas de dicha Convención. Cuando la Corte IDH emite una Opinión Consultiva, ejerce una competencia convencional otorgada mediante la ratificación de dicho instrumento por parte de los mismos Estados. Si bien la CADH no ha reconocido expresamente el mismo efecto vinculante a las Opiniones Consultivas que a las sentencias de la Corte IDH, es indiscutible que, como opinión autorizada del organismo interamericano competente para interpretar la $\mathrm{CADH}$, estas opiniones gocen de una autoridad que los Estados, incluido el ecuatoriano, deben observar.

Con frecuencia, los jueces se enfrentan a la tensión que puede producirse cuando el texto constitucional tiene disposiciones contrarias o incompatibles con la interpretación que la Corte IDH ha realizado en el marco de sus Opiniones Consultivas. Ello ocurre en Ecuador, por ejemplo, cuando el texto constitucional en su artículo 67 define el matrimonio como la unión entre hombre y mujer, mientras que la Opinión Consultiva 24/17 de la Corte IDH interpretó un artículo similar de la CADH en el sentido de que todas las parejas, incluidas aquellas del mismo sexo, deben poder acceder a todas las figuras de protección de la familia, incluido el matrimonio.

Frente a esta tensión, en este artículo reflexionaremos sobre el valor de las Opiniones Consultivas de la Corte IDH tanto a la luz del Derecho Internacional Público (en adelante DIP) como a la luz del derecho interamericano expresado en las interpretaciones de la propia Corte IDH. Luego, examinaremos el valor que la Corte Constitucional del Ecuador (en adelante Corte Constitucional) ha otorgado a las Opiniones Consultivas de la Corte IDH.

* El artículo fue sometido a la revista FORO el 23 de octubre de 2018 (previo a las sentencias de la Corte Constitucional del Ecuador sobre matrimonio igualitario). 
Reconocemos que existen posturas contrarias, tanto a nivel nacional e internacional, que -desde una perspectiva más formalista de las fuentes del derecho- consideran que la Opinión Consultiva 24/17 no es de obligatoria aplicación bajo el ordenamiento jurídico ecuatoriano. Esta tesis se fundamenta, principalmente, en que la Opinión Consultiva 24/17: i. es resultado de la función consultiva de la Corte IDH y, considerarla de obligatorio cumplimiento, desnaturalizaría la función interpretativa y consultiva de la Corte IDH; ii. la Corte IDH incurrió en un vicio extra petita, pues en las preguntas formuladas por Costa Rica jamás se consultó si el matrimonio entre personas del mismo sexo debía ser legalizado; iii. la $\mathrm{CADH}$ no reconoce que las opiniones consultivas sean de carácter obligatorio.

Ahora bien, más allá del debate doctrinario o jurisprudencial, en este artículo aportaremos argumentos para sostener que el valor privilegiado que se asigna en el derecho interno ecuatoriano a las decisiones de organismos internacionales de protección de derechos humanos tiene una implicación práctica ineludible en el efectivo goce de los derechos. De ahí que analizaremos críticamente los argumentos esgrimidos por los jueces de la Corte Provincial, quienes, actuando como jueces constitucionales, desconocieron el valor de las Opiniones Consultivas como fuente vinculante y rechazaron las pretensiones de los accionantes que buscaban registrar su vínculo familiar, como parejas del mismo sexo, bajo la figura del matrimonio, fundamentándose en las disposiciones de la Opinión Consultiva OC-24/17 sobre identidad de género, e igualdad y no discriminación a parejas del mismo sexo (en adelante OC-24/17).

\section{OBLIGATORIEDAD DE LAS OPINIONES CONSULTIVAS A LA LUZ DEL DERECHO INTERNACIONAL PÚBLICO}

La interpretación de los tratados internacionales constituye una operación determinante para la correcta aplicación de las disposiciones convencionales. Afortunadamente, para orientar el complejo ejercicio intelectual de interpretación de tratados internacionales existe una serie de reglas recogidas en los artículos 31 y 32 de la Convención de Viena sobre el Derecho de los Tratados de 1969 (en adelante Convención de Viena), que están inspiradas en el principio de buena fe. La Corte Internacional de Justicia ha afirmado en reiteradas ocasiones que "un tratado debe ser interpretado de buena fe conforme al sentido ordinario que haya de atribuir a sus términos en su contexto y a la luz de su objeto y fin". ${ }^{1}$

1. Corte Internacional de Justicia, "Fallo de 3 de febrero de 1994", Caso relativo a la controversia territorial Jamahiriya Árabe Libia/Chad, 3 de febrero de 1994, 22, 〈https:/www.dipublico.org/cij/doc/97.pdf〉. Vid, 
Por ende, bajo el marco del DIP -en particular de la Convención de Viena-, si un Estado en ejercicio de su soberanía ratifica un tratado, debe ceñirse a lo establecido en él, ${ }^{2}$ obligación que conlleva la de adoptar la interpretación autorizada respecto del significado y alcance de sus disposiciones, emitida por el órgano competente. ${ }^{3}$

En otras palabras, si un Estado suscribe un tratado que crea un organismo autorizado para interpretar sus disposiciones, se obliga a cumplir de buena fe la interpretación que el organismo autorizado realice. En consecuencia, debido a que el Estado ecuatoriano ratificó la $\mathrm{CADH}$, y que dicho tratado creó la Corte IDH y le asignó la facultad de emitir Opiniones Consultivas, Ecuador está obligado a honrar lo pactado y cumplir de buena fe la interpretación autorizada de la Corte IDH.

\section{OBLIGATORIEDAD DE LAS OPINIONES CONSULTIVAS A LA LUZ DE LOS ESTÁNDARES FIJADOS POR LA CORTE IDH: EVOLUCIÓN DE SU PROPIO CRITERIO}

La Corte IDH es el máximo órgano jurisdiccional del Sistema Interamericano de Derechos Humanos (en adelante SIDH). Sus competencias contenciosa y consultiva se encuentran reguladas en los artículos $44^{4}$ y $64^{5}$ de la CADH, respectivamente. $\mathrm{La}$ facultad consultiva de la Corte IDH tiene por objeto "coadyuvar al cumplimiento de las obligaciones internacionales de los Estados. Se trata de un método judicial alterno, por medio del cual se puede lograr la interpretación de la Convención sub examine, y de otros tratados atinentes a los derechos humanos en el sistema interamericano". ${ }^{6}$

Como lo ha reconocido la propia Corte IDH, dicha facultad constituye "la más amplia función consultiva que se haya confiado a tribunal internacional alguno hasta el presente". ${ }^{7}$ En esta misma línea, la Corte IDH se ha pronunciado sobre las

Corte Internacional de Justicia, "Fallo de 13 de diciembre de 1999, Caso relativo a la isla Kasikili/Sedudu entre Botswana y Namibia, 13 de diciembre de 1999, 18, 〈https://www.dipublico.org/cij/doc/127.pdf;; Corte Internacional de Justicia, "Fallo de 27 de junio de 2001", Caso relativo a LaGrand, 27 de junio de 2001, párr. 99.

2. Manuel Diez de Velasco, Instituciones de Derecho Internacional Público (Madrid: Tecnos, 2002), 85.

3. Rafael Nieto-Navia, "El valor jurídico de las recomendaciones de los Comités de Derechos Humanos y el bloque de constitucionalidad", 18 International Law. Revista Colombiana de Derecho Internacional, 155, n. ${ }^{\circ} 190$ (2011): 164-6.

4. Convención Americana de Derechos Humanos, 1969, art. 44.

5. Ibíd.

6. Juan Carlos Hitters y Óscar Fappiano, Derecho Internacional de los Derechos Humanos (Buenos Aires: Ediar, 1999), 317.

7. Corte IDH, Opinión Consultiva 1/82 del 24 de septiembre de 1982, "Otros tratados" objeto de la función consultiva de la Corte, de 24 de septiembre de 1982, 14. 
materias que pueden someterse al conocimiento de su facultad consultiva, determinando que:

la competencia consultiva de la Corte puede ejercerse, en general, sobre toda disposición concerniente a la protección de los derechos humanos, de cualquier tratado internacional aplicable en los Estados americanos, con independencia de que sea bilateral o multilateral, de cuál sea su objeto principal o de que sean o puedan ser partes del mismo Estados ajenos al sistema interamericano. ${ }^{8}$

Tanto en su Reglamento como en sus dictámenes, la Corte IDH ha distinguido entre sus competencias contenciosa y consultiva. En un momento inicial, la Corte IDH se pronunció sobre las diferencias entre sus competencias en los siguientes términos: en un procedimiento contencioso, la Corte debe no solo interpretar las normas aplicables, establecer la veracidad de los hechos denunciados y decidir si los mismos pueden ser considerados como una violación de la Convención imputable a un Estado Parte, sino también, si fuera del caso, disponer que se garantice al lesionado en el goce de su derecho o libertad conculcados, en el entendido de que los Estados Parte en este proceso están sujetos a cumplir obligatoriamente el fallo de la Corte. En cambio, en materia consultiva, la Corte no está llamada a resolver cuestiones de hecho para verificar su existencia sino a emitir su opinión sobre la interpretación de una norma jurídica. ${ }^{9} \mathrm{La}$ misma Corte IDH ha señalado, sobre la naturaleza de su competencia consultiva, que la amplitud de términos en que ha sido concebida dicha función,

crea un sistema paralelo al del artículo 62 y ofrece un método judicial alterno de carácter consultivo, destinado a ayudar a los Estados y órganos a cumplir y a aplicar tratados en materia de derechos humanos sin someterlos al formalismo y al sistema de sanciones que caracteriza el proceso contencioso. ${ }^{10}$

Las expresiones relativamente ambiguas empleadas por la Corte IDH -como la referida en el punto anterior- podrían dar cuenta de que dicho órgano ha restado importancia a sus opiniones consultivas. Ahora bien, en palabras de autores como Pedro Nikken, estas expresiones de la Corte IDH estaban destinadas, "a explicar y a afirmar la amplitud de su función consultiva y no a debilitarla", ${ }^{11}$ por ello las Opiniones Con-

8. Ibíd., párr. 50.

9. Corte IDH, “Opinión Consultiva OC-3/83 del 8 de septiembre de 1983 sobre las restricciones a la pena de muerte" de 8 de septiembre de 1983, párr. 32.

10. Ibíd., párr. 43.

11. Pedro Nikken, "La función consultiva de la Corte Interamericana de Derechos Humanos", Instituto de Investigaciones Jurídicas de la Universidad Nacional Autónoma de México, 15 (1999), 〈https://archivos. juridicas.unam.mx/www/bjv/libros/5/2454/10.pdf . 
sultivas son utilizadas como jurisprudencia que sustenta los casos contenciosos de la Corte IDH. Otros autores han ido aún más allá. Héctor Faúndez Ledezma afirma que las Opiniones Consultivas no solo están dotadas de la autoridad del órgano del cual emanan, sino que poseen un efecto jurídico vinculante, derivado de la propia Convención y que no se puede eludir por los Estados Parte en la misma. ${ }^{12} \mathrm{~A}$ su vez, el artículo 1 del Estatuto de la Corte IDH define a este organismo como

una institución judicial autónoma cuyo objetivo es la aplicación e interpretación de la Convención Americana sobre Derechos Humanos. Es así como, [...] al ejercer, sea en el campo contencioso, sea en el consultivo, la función de "aplicar o interpretar" el Pacto de San José, la Corte actúa como un órgano jurisdiccional y sus decisiones tienen naturaleza jurisdiccional. ${ }^{13}$

Años más tarde, realizando una interpretación teleológica y evolutiva respecto de la $\mathrm{CADH}$, de otros instrumentos del SIDH y, finalmente, de su propia competencia, dicho órgano determinó:

aún cuando la opinión consultiva de la Corte no tiene el carácter vinculante de una sentencia en un caso contencioso, tiene, en cambio, efectos jurídicos innegables. De esta manera, es evidente que el Estado u órgano que solicita a la Corte una opinión consultiva no es el único titular de un interés legítimo en el resultado del procedimiento (énfasis añadido). ${ }^{14}$

De manera más reciente, la Corte IDH se pronunció nuevamente sobre la obligatoriedad de sus opiniones consultivas en relación con la obligación de todos los órganos estatales de realizar el correspondiente control de convencionalidad, aclarando en cierta forma su postura inicial al respecto. Así, en la Opinión Consultiva OC-23/17 de 15 de noviembre de 2017, la Corte estimó necesario recordar a los Estados lo siguiente:

Es por tal razón que estima necesario que los diversos órganos del Estado realicen el correspondiente control de convencionalidad para la protección de todos los derechos humanos, también sobre la base de lo que señale en ejercicio de su competencia consultiva, la que innegablemente comparte con su competencia contenciosa el propósito del sistema

12. Héctor Faúndez Ledesma, El sistema interamericano de protección de los derechos humanos: aspectos institucionales y procesales, 2. ${ }^{\text {a }}$ ed. (Costa Rica: Editorial IIDH, 1999), 603-10.

13. Nikken, "La función consultiva de la Corte Interamericana de Derechos Humanos", 12.

14. Corte IDH, "Opinión Consultiva OC-15/97 del 14 de noviembre de 1997 sobre informes de la Comisión Interamericana sobre Derechos Humanos", 14 de noviembre de 1997, párr. 26. 
interamericano de derechos humanos, cual es, la protección de los derechos fundamentales de los seres humanos. ${ }^{15}$

Así, la Corte IDH determinó que la emisión de una opinión consultiva obliga a todos los Estados miembros de la OEA, "incluyendo a los que no son Parte de la Convención $[\mathrm{CADH}]$ pero que se han obligado a respetar los derechos humanos en virtud de la Carta de la OEA (artículo 3.1) y la Carta Democrática Interamericana (artículos 3, 7, 8 y 9)". ${ }^{16}$ De esta manera, se configura para los Estados una fuente "que, acorde a su propia naturaleza, contribuye también y especialmente de manera preventiva, a lograr el eficaz respeto y garantía de los derechos humanos" ${ }^{17}$

La interpretación de la $\mathrm{CADH}$, “cuando resulta de una opinión consultiva de la Corte, no es una interpretación cualquiera, pues se trata de conclusiones obtenidas por el órgano que la misma Convención creó con el propósito de interpretar[la]". ${ }^{18}$ Las opiniones consultivas de la Corte IDH constituyen, entonces, una interpretación autorizada del alcance de las obligaciones internacionales directamente relacionadas con la protección de los derechos humanos, las cuales han sido asumidas por los Estados miembros del SIDH a través de la ratificación de tratados internacionales de derechos humanos. ${ }^{19}$

\section{EL BLOQUE DE CONSTITUCIONALIDAD: DIRECTA APLICABILIDAD DE LOS INSTRUMENTOS INTERNACIONALES DE DERECHOS HUMANOS EN ECUADOR}

En el sistema ecuatoriano, el bloque de constitucionalidad encuentra su fundamento en los artículos 11.3 y 426 de la Constitución, ${ }^{20}$ que se refieren a la directa aplicabi-

15. Corte IDH, "Opinión Consultiva OC-23/17 del 15 de noviembre de 2017 sobre Medio Ambiente y Derechos Humanos", 15 de noviembre de 2017, párr. 28. Vid., Corte IDH, "Opinión Consultiva OC-24/17 del 24 de noviembre de 2017 sobre identidad de género, e igualdad y no discriminación a parejas del mismo sexo", 24 de noviembre de 2017, párr. 26.

16. Corte IDH, “Opinión Consultiva OC-24/17 del 24 de noviembre de 2017”, ibíd., párr. 27.

17. Ibíd.

18. Nikken, "La función consultiva de la Corte Interamericana de Derechos Humanos", 14.

19. Corte IDH, “Opinión Consultiva OC-1/83 del 24 de septiembre de 1982 sobre 'otros tratados' objeto de la facultad consultiva de la Corte", 24 de septiembre de 1982, párr. 21.

20. Ecuador Corte Constitucional del Ecuador, "Sentencia", en Juicio n. ${ }^{\circ}$ 026-12-SIS-CC, 21 de junio de 2012, 12: "Una constitución puede ser normativamente algo más que el propio texto constitucional, esto es, que las normas constitucionales, o al menos supralegales, pueden ser más numerosas que aquellas que pueden encontrarse en el articulado de la constitución escrita. El bloque de constitucionalidad nos permite interpretar las normas constitucionales, pero, además, los tratados de derechos humanos orientan al Juez constitucional a identificar elementos esenciales que definan la fisonomía insustituible de la Constitución. 
lidad de las normas constitucionales, disposiciones y estándares contenidos en instrumentos internacionales de derechos humanos que reconocen derechos más favorables que los contenidos en la norma suprema. En palabras de la Corte Constitucional,

al bloque de constitucionalidad se lo entiende como aquel conjunto de normas que no constando expresamente dentro de las normas positivas de la Constitución formal, forman parte de esta porque es la propia Constitución la que reconoce ese rango y rol, en virtud del más alto valor del Estado: la protección de la dignidad humana. ${ }^{21}$

Así, por referencia expresa de la Constitución a instrumentos internacionales, los derechos reconocidos en ellos han pasado a formar parte del bloque de constitucionalidad y son directamente aplicables en Ecuador sin que sea necesaria una mención expresa de la norma suprema.

Vale enfatizar que, a efectos de dar aplicabilidad real a aquellos "instrumentos internacionales" de derechos humanos que reconocen derechos más favorables que la Constitución, el legislador constituyente prefirió dicho término por sobre otros esencialmente distintos como "convenciones internacionales" o "tratados internacionales". En consecuencia, el término "instrumentos internacionales de derechos humanos" 22 permite la directa aplicabilidad no solo de tratados o convenciones, sino de otro tipo de instrumentos, como son las interpretaciones autorizadas que realizan los organismos internacionales de derechos humanos respecto de la convención cuyo cumplimiento supervisan, siempre y cuando sean más favorables que las normas establecidas en la Constitución.

Por lo mismo, la constante referencia que hacen las normas constitucionales a los "instrumentos internacionales de derechos humanos", y no solo a los "tratados internacionales de derechos humanos", genera que las normas contenidas en esos instrumentos se encuentren incorporadas a la Constitución y formen parte del bloque de constitucionalidad.

Las Opiniones Consultivas están tan incorporadas a la Constitución que se ha establecido una garantía que permite exigir su cumplimiento, protegiendo así a estos instrumentos como parte de la supremacía constitucional: la acción por incumplimiento. La Ley Orgánica de Garantías Jurisdiccionales y Control Constitucional (en adelante LOGJCC), al regular esta acción en su artículo 52, aclara que tiene por objeto garan-

En tal virtud, para resolver un problema jurídico no solo se debe tener presente a la Constitución, ya que otras disposiciones y principios pueden tener relevancia para decidir esos asuntos".

21. Ecuador Corte Constitucional del Ecuador, "Sentencia", en Juicio n. ${ }^{\circ} 004-14-S C N-C C, 6$ de agosto de 2014.

22. Ecuador, Constitución de la República del Ecuador, Registro Oficial 449, 20 de octubre de 2008, art. 11. 
tizar el cumplimiento de "sentencias, decisiones o informes" de organismos internacionales de protección de derechos humanos. Nótese que no se hace diferenciación entre una sentencia, un informe y otras "decisiones", término que, sin lugar a dudas, abarca a las Opiniones Consultivas de la Corte IDH, pues, ¿qué serían las Opiniones Consultivas si no fueran decisiones de esta Corte?

\section{OBLIGATORIEDAD DE LAS OPINIONES CONSULTIVAS A LA LUZ DE LOS ESTÁNDARES FIJADOS POR LA CORTE CONSTITUCIONAL DEL ECUADOR: APLICACIÓN EN SUS DICTÁMENES}

La Corte Constitucional, máximo órgano de control, interpretación y administración de justicia constitucional en Ecuador, ${ }^{23}$ ha aplicado en innumerables ocasiones los estándares fijados por la Corte IDH en sus Opiniones Consultivas, afirmando que no es posible desconocer el razonamiento que en ellos plasma la Corte IDH. ${ }^{24}$

En su sentencia n. ${ }^{\circ}$ 003-14-SIN-CC de 17 de septiembre de 2014, la Corte Constitucional recogió la argumentación de la Corte IDH en su Opinión Consultiva OC-5/85 de 13 de noviembre de 1985 para fundamentar su decisión sobre la naturaleza del derecho de libertad de expresión y de rectificación o respuesta. ${ }^{25}$ Lo mismo ocurrió en la sentencia n. ${ }^{\circ}$ 064-15-SEP-CC de 11 de marzo de 2015, en la cual la Corte Constitucional hace propio el análisis realizado por la Corte IDH en su Opinión Consultiva OC-21/2014 de 19 de agosto de 2014, ${ }^{26}$ y en su Opinión Consultiva OC-17/2002 de 28 de agosto de 2002. ${ }^{27}$ En la sentencia n. ${ }^{\circ}$ 019-16-SIN-CC de 22 de marzo de 2016, la Corte Constitucional desarrolla los límites admisibles al derecho a la igualdad ante la ley fundamentándose, una vez más, en el contenido de la Opinión Consultiva n. ${ }^{\circ}$ OC-17/2002 de 28 de agosto de $2002 .{ }^{28}$

23. Ibíd., art. 429.

24. Ecuador Corte Constitucional del Ecuador, "Sentencia", en Juicio n. ${ }^{\circ}$ 003-14-SIN-CC, 17 de septiembre de 2014. "La Corte Constitucional, haciendo propia la reflexión de la Corte Interamericana de Derechos Humanos acerca de las esferas de la libertad de opinión, desde la opinión consultiva OC-5/85, no puede desconocer que el derecho a la libertad de expresión no debe vincularse solo con el aspecto individual, sino también con el colectivo [...]", 59.

25. Ibíd., 59, 72, 130.

26. Ecuador Corte Constitucional del Ecuador, "Sentencia", en Juicio n. ${ }^{\circ}$ 064-15-SEP-CC, 11 de marzo de 2015, 18.

27. Ibíd., 19.

28. Ecuador Corte Constitucional del Ecuador, "Sentencia", en Juicio n. ${ }^{\circ}$ 019-16-SIN-CC, 22 de marzo de 2016, 15-6. 
Como se vislumbra en los dictámenes referidos, estos estándares son de trascendental importancia en la configuración argumentativa de las decisiones de la Corte Constitucional. Si lo anterior no resulta suficiente, en uno de sus casos más recientes (conocido como el Caso Satya), la Corte Constitucional afirmó que se tratan de instrumentos internacionales de derechos humanos que,

por expresa disposición del artículo 424 de la Constitución de la República y por constituir interpretación oficial del órgano interamericano encargado de determinar el sentido y alcance de las disposiciones convencionales relacionadas con la protección de derechos humanos, se entiende adherido al texto constitucional y es de aplicación directa, inmediata y preferente, en tanto su contenido sea más favorable para el efectivo ejercicio y protección de los derechos reconocidos. ${ }^{29}$

En definitiva, lo anterior da cuenta de que el máximo órgano de control, interpretación y administración de justicia constitucional en Ecuador ha fijado un precedente claro respecto del lugar que ocupan las Opiniones Consultivas de la Corte IDH en el sistema ecuatoriano. De manera que, en la medida en que estos pronunciamientos contengan estándares más favorables al pleno goce y ejercicio de los derechos reconocidos en la Constitución, se aplicarán de manera directa, inmediata y preferente. ${ }^{30}$

Es preciso recordar que el control de convencionalidad constituye un mecanismo básico para la garantía de los derechos, en la medida en que permite que los órganos jurisdiccionales, además de analizar sus disposiciones internas, recurran a los instrumentos internacionales y a la interpretación que de estos se realice, ${ }^{31}$ tal como señala la propia Corte Constitucional:

el control de convencionalidad se constituye en un mecanismo básico para la garantía de los derechos, en tanto permite que los órganos jurisdiccionales no se limiten a un análisis de sus disposiciones internas, sino que además recurran a los instrumentos internacionales y la interpretación efectuada de estos, a fin de dotar de contenido integral a los derechos. ${ }^{32}$

Es claro que, según la Corte Constitucional, todo juez y toda autoridad pública están obligados a controlar que sus actos sean compatibles con la Convención y con la

29. Ecuador Corte Constitucional del Ecuador, "Sentencia", en Juicio n. ${ }^{\circ}$ 184-18-SEP-CC, 29 de mayo de 2018, 58.

30. Ecuador, Constitución de la República del Ecuador, Registro Oficial 449, 20 de octubre de 2008, art. 11.3 y 424.

31. Ecuador Corte Constitucional del Ecuador, "Sentencia", en Juicio n. ${ }^{\circ}$ 003-14-SIN-CC, 17 de septiembre de 2014, 20.

32. Corte Constitucional, "Sentencia”, en Caso Ley Orgánica de Comunicación 0014-13-IN, 0023-13-IN, 0028-13-IN y acumulados. 
interpretación autorizada que de ella efectúa la Corte IDH. Desconocer la interpretación autorizada de la Corte IDH podría comprometer la responsabilidad internacional del Estado ecuatoriano en casos contenciosos posteriores.

\section{RECUENTO DE LOS ESTÁNDARES FIJADOS POR LA CORTE IDH EN LA OPINIÓN CONSULTIVA OC-24/17}

Una vez precisada la obligatoriedad de las Opiniones Consultivas a la luz del DIP, del DIDH y del derecho interno, se procederá a estudiar los estándares fijados por la OC-24/17 y su impacto en la administración de justicia constitucional en Ecuador. Así, se expondrán las principales conclusiones de la Corte IDH en respuesta a la consulta formulada por Costa Rica. En segunda instancia, se analizará la aplicación práctica de la OC-24/17 en Ecuador y las decisiones contradictorias emitidas.

En el año 2016, amparado en el artículo 64 de la CADH, el Estado de Costa Rica consultó a la Corte IDH sobre el alcance del derecho a la identidad de género, el derecho al cambio de nombre a partir de la identidad de género y el reconocimiento de los derechos patrimoniales derivados del vínculo entre personas del mismo sexo, a la luz de las disposiciones de la CADH y su desarrollo. El pasado 24 de noviembre de 2017, la Corte IDH emitió la OC-24/17 en respuesta a la consulta formulada.

En este pronunciamiento, la Corte IDH determinó que no debe hacerse una interpretación restrictiva del concepto de "familia" que excluya de la protección interamericana al vínculo afectivo entre parejas del mismo sexo, puesto que ello sería contrario al objeto y fin de la $\mathrm{CADH} .{ }^{33}$ En criterio de la Corte, las parejas del mismo sexo deben gozar de iguales derechos que los generados por el vínculo familiar de parejas heterosexuales. ${ }^{34}$ En este sentido, consideró que no es admisible la existencia de dos clases de uniones solemnes para consolidar la convivencia de parejas del mismo sexo puesto que "se configuraría una distinción fundada en la orientación sexual de las personas, que resultaría discriminatoria, y por tanto incompatible con la Convención Americana". Finalmente, la OC-24/17 estableció que se deben proteger, sin discriminación alguna con respecto a las parejas entre personas heterosexuales, todos los derechos patrimoniales que se derivan del vínculo familiar protegido entre personas del mismo sexo. ${ }^{35}$

33. Ibíd., párr. 189.

34. Ibíd., párr. 192.

35. Ibíd., párr. 198. 


\section{APLICACIÓN PRÁCTICA DE LA OC-24/17 EN ECUADOR: ANÁLISIS Y CRÍTICA A LAS SENTENCIAS DE LA CORTE PROVINCIAL}

Como se ha precisado en las secciones anteriores, las Opiniones Consultivas de la Corte IDH deben ser aplicadas en Ecuador de manera directa, inmediata y preferente siempre que contengan estándares más favorables al pleno goce y ejercicio de los derechos reconocidos en la Constitución. Sin embargo, este no siempre ha sido el caso. A raíz de la OC-24/17, se han emitido fallos contradictorios que, por un lado, reconocen el valor jurídico de este instrumento y, por otro, desconocen su obligatoriedad.

El valor jurídico de la OC-24/17 no solo ha sido reconocido en la sentencia $n .{ }^{\circ}$ 184-18-SEP-CC de la Corte Constitucional, ${ }^{36}$ sino que, incluso, juzgadores de primera instancia, con el afán de asegurar y garantizar el goce efectivo de los derechos, se han referido a este instrumento internacional para fundamentar sus decisiones. En la acción de protección n. $^{\circ}$ 01204-2018-3635, a la hora de resolver la pretensión de una pareja del mismo sexo que buscaba unirse bajo la figura del matrimonio, la jueza de la Unidad Judicial de la Familia Mujer, Niñez y Adolescencia determinó:

el Ecuador es parte de la Convención Americana de Derechos Humanos; [...] el Gobierno del Ecuador declara que reconoce como obligatoria de pleno derecho y sin convención especial, la competencia de la Corte Interamericana de Derechos Humanos sobre todos los casos relativos a la interpretación o aplicación de la Convención [...]. Es entonces indudable la obligatoriedad del Estado Ecuatoriano en vincular la Opinión Consultiva. 2.Por mandato del art. 426 de la Constitución de la República todas las personas, autoridades. Las juezas y jueces, autoridades administrativas y servidoras y servidores públicos, aplicarán directamente las normas constitucionales y las previstas en los instrumentos internacionales de derechos humanos siempre que sean más favorables a las establecidas en la Constitución, aunque las partes no las invoquen expresamente [... ]. Por lo expuesto el Órgano Judicial a través de esta Juzgadora, está en la obligación de aplicar también como lo hizo la Corte Constitucional la Opinión Consultiva OP-24/17 [...] (énfasis añadido). ${ }^{37}$

Este criterio se replicó en el proceso signado con el n. ${ }^{\circ}$ 1204-2018-3637 al de resolver una acción de protección de similar naturaleza. Por lo tanto, administrando

36. En la sentencia n. ${ }^{\circ}$ 184-18-SEP-CC, caso Satya, la Corte Constitucional fijó un precedente claro respecto del valor jurídico y la aplicación directa que tienen las Opiniones Consultivas de la Corte IDH en el ordenamiento jurídico ecuatoriano, específicamente, la OC-24/17. Vid., Ecuador Corte Constitucional del Ecuador, "Sentencia", en Juicio n. ${ }^{\circ}$ 184-18-SEP-CC, 29 de mayo de 2018, 58.

37. Ecuador Unidad Judicial de Familia Mujer, Niñez y Adolescencia, "Sentencia", en Juicio n. ${ }^{\circ} 01204-$ 20180-3635, 16 de julio de 2018. 
justicia constitucional, los operadores de justicia, en aras de salvaguardar los derechos fundamentales contenidos en la Constitución y en instrumentos internacionales, han respetado el valor jurídico vinculante de la OC-24/17. No obstante, como se demostrará a continuación, el actuar de la función judicial no ha sido uniforme.

El 10 de septiembre de 2018 la Corte Provincial del Azuay resolvió la apelación presentada dentro del caso n. ${ }^{\circ}$ 01204-2018-03637 y afirmó que: "las opiniones consultivas están para coadyuvar la protección de derechos, pero no son vinculantes" (énfasis añadido). ${ }^{38}$ De igual manera, en el caso n. ${ }^{\circ} 01204-2018-03635$, la misma Corte estableció que la Opinión Consultiva OC-24/17, por su naturaleza, no es vinculante ni obligatoria para el Estado ecuatoriano. ${ }^{39}$ En esta misma línea se ha pronunciado la Corte Provincial de Pichincha dentro del proceso n. ${ }^{\circ}$ 17159-2018-00006, alegando que las opiniones consultivas no son obligatorias:

lo que constituye la principal diferencia con las sentencias. Y no son vinculantes, no solo porque, de lo contrario, no existiría diferencia con estas últimas, sino porque, además, en ellas no hay partes, de donde se desprende que sería del todo injusto que una resolución de la Corte fuese obligatoria para los que no han comparecido ante ella ni han sido demandados o interpelados. ${ }^{40}$

A continuación, se analizarán los principales argumentos -cuestionables, como mínimo- en los cuales la Corte Provincial del Azuay y de Pichincha fundamentan el criterio antedicho, a saber, que: i. por el principio de jerarquía normativa, la Constitución prevalece sobre la OC-24/17; ii. la Corte Constitucional es la única facultada para declarar la inconstitucionalidad de normas jurídicas; iii. la Corte IDH ha incurrido en un vicio extrapetita; y iv. el voto disidente del juez Eduardo Vio Grossi establece que las Opiniones Consultivas no son vinculantes.

\section{EN VIRTUd DEL PRINCIPIO DE JERARQUía NORMATIVA, ¿PRima la Constitución sobre las Opiniones Consultivas?}

Para la Corte Provincial, la aplicación de la jerarquía normativa deviene en la primacía de la Constitución por sobre las Opiniones Consultivas:

38. Ecuador Corte Provincial de Justicia de Azuay Sala Penal, "Sentencia", en Juicio n. ${ }^{\circ}$ 01204-2018-03637, 10 de septiembre de 2018.

39. Ecuador Corte Provincial de Justicia de Azuay Sala Laboral, "Sentencia", en Juicio n. ${ }^{\circ}$ 01204-201803635, 10 de septiembre de 2018.

40. Ecuador Corte Provincial de Justicia de Pichincha Sala Civil y Mercantil, "Sentencia", en Juicio n. ${ }^{o}$ 17159-2018-00006, 16 de octubre de 2018. 
Inclusive en el supuesto no consentido que se quisiera tener en cuenta dicha Opinión Consultiva; sin embargo el art. 425 de la CRE, en concordancia con el análisis anterior, determina en forma imperativa que el orden jerárquico para la aplicación de las normas, es y como no puede ser de otra manera, en primer lugar la Constitución; y luego los tratados y convenios internacionales; $y$, en la especie, como hemos indicado, la opinión no reúne las características de un tratado, ni es una sentencia $[\ldots] .{ }^{41}$

Para fundamentar dicha interpretación, los jueces de la Corte Provincial analizan de manera aislada el artículo 425 de la norma suprema, que se refiere únicamente a tratados y convenios internacionales, ${ }^{42}$ dejando de lado el contenido de los artículos constitucionales que garantizan la directa aplicabilidad de los instrumentos internacionales de derechos humanos que reconocen derechos más favorables que los contenidos en la Constitución.

Así, si bien el artículo 424 de la Constitución señala que esta es la norma suprema, añade que "la Constitución y los tratados internacionales de derechos humanos ratificados por el Estado que reconozcan derechos más favorables a los contenidos en la Constitución, prevalecerán sobre cualquier otra norma jurídica o acto del poder público". Esta norma debe leerse en conjunto con el artículo 417, según el cual "en el caso de los tratados y otros instrumentos internacionales de derechos humanos se aplicarán los principios pro ser humano, de no restricción de derechos, de aplicabilidad directa y de cláusula abierta establecidos en la Constitución". ${ }^{43}$ Así, de una lectura integral y sistemática de la Constitución, es claro que los instrumentos internacionales de derechos humanos en Ecuador gozan de una jerarquía privilegiada al punto que incluso podrían ser aplicados por sobre la Constitución cuando sus normas sean más favorables para la protección de los derechos.

La argumentación de la Corte Provincial desconoce incluso el contenido del artículo 427 de la Carta Magna, el cual prescribe: "las normas constitucionales se interpretarán por el tenor literal que más se ajuste a la Constitución en su integralidad" (énfasis añadido). ${ }^{44}$ Precisamente, la Constitución en su conjunto pretende garantizar el pleno goce y ejercicio de derechos, sin perjuicio de que su desarrollo se encuentre contenido en instrumentos internacionales que no tengan la naturaleza de un tratado o convenio internacional. Al respecto, la Corte Constitucional ha señalado que:

41. Ecuador Corte Provincial de Justicia de Azuay Sala Laboral, "Sentencia", en Juicio n. ${ }^{\circ}$ 01204-201803635, 10 de septiembre de 2018.

42. Ecuador, Constitución de la República del Ecuador, Registro Oficial 449, 20 de octubre de 2008, art. 425.

43. Ibíd., art. 417.

44. Ibíd., art. 427. 
para el examen de constitucionalidad la Corte Constitucional no debe efectuar únicamente su análisis fundamentándose en la contraposición de la disposición impugnada con el texto constitucional, sino además con los instrumentos internacionales de derechos humanos, [...] tomando en consideración la Convención Americana de Derechos Humanos, las sentencias que dotan de contenido a la Convención emitidas por la Corte Interamericana de Derechos Humanos y todos aquellos instrumentos internacionales de derechos humanos ratificados por el Ecuador; en suma, aquello que se denomina el ius comune interamericano (énfasis añadido). ${ }^{45}$

De esta manera, la OC-24/17, como instrumento internacional que reconoce derechos más favorables que los contenidos en la Constitución, prevalece sobre la norma suprema y, sin lugar a duda, debió ser aplicada de manera preferente en pos de la plena vigencia de los derechos.

\section{Frente a la facultad privativa de la Corte Constitucional PARA DECLARAR LA INCONSTITUCIONALIDAD DE NORMAS JURÍDICAS, ¿CUÁL ES EL DEBER DE LOS JUECES?}

De conformidad con el artículo 142 de la LOGJCC,

cualquier jueza o juez, de oficio o a petición de parte, solo si tiene duda razonable y motivada de que una norma jurídica es contraria a la Constitución o a los instrumentos internacionales de derechos humanos que establezcan derechos más favorables que los reconocidos en la Constitución, suspenderá la tramitación de la causa y remitirá en consulta el expediente a la Corte Constitucional. ${ }^{46}$

Es así que, en caso de que un juez tenga duda razonable y motivada sobre posibles contradicciones entre una disposición normativa y el bloque de constitucionalidad, deberá elevar la norma en consulta al máximo órgano de administración de justicia constitucional.

En la sentencia dictada dentro del proceso n. ${ }^{\circ}$ 01204-2018-3637, la Corte Provincial recoge este criterio:

en el Ecuador existe el control concentrado, por lo que solamente a la Corte Constitucional le corresponde declarar la inconstitucionalidad de las normas, de ser el caso, y al no existir

45. Ecuador Corte Constitucional del Ecuador, "Sentencia", en Juicio n. ${ }^{\circ}$ 003-14-SIN-CC, 17 de septiembre de 2014, 19.

46. Ecuador, Ley de Garantías Jurisdiccionales y Control Constitucional, Registro Oficial 52, 22 de octubre de 2009, art. 142. 
tal declaración, las normas mencionadas, son constitucionales y se encuentran plenamente vigentes. $^{47}$

En el razonamiento empleado por los jueces provinciales se vislumbra la omisión de un análisis de la existencia de posibles contradicciones entre disposiciones infraconstitucionales y disposiciones contenidas en instrumentos internacionales de derechos humanos que reconocen derechos más favorables que los establecidos en la Constitución.

En el presente caso, existe un instrumento internacional de derechos humanos -la OC-24/17- que reconoce el derecho a contraer matrimonio para personas del mismo sexo y normas constitucionales ${ }^{48}$ e infraconstitucionales ${ }^{49}$ evidentemente contrarias. Ante esta evidente contradicción entre normas constitucionales e infraconstitucionales, los jueces debieron suspender la tramitación de la causa y remitir el expediente en consulta a la Corte Constitucional para que sea esta la que resuelva sobre la constitucionalidad de la norma. Lejos de cumplir esta obligación, los jueces presumieron la constitucionalidad de las normas que estaban llamados a interpretar a la luz de la OC-24/17 y, así, incumplieron su obligación de aplicar los estándares más favorables contenidos en dicho instrumento directamente.

\section{LA CORTE IDH ¿incurrió EN UN VICIO de EXTRA PETITA en su Opinión Consultiva OC-24/17?}

En palabras de la Corte Provincial, "en la opinión consultiva OC-24/17, la CIDH [sic] incurrió en el vicio de extra petita, por cuanto la consulta de [dicho] Gobierno fue únicamente sobre los derechos patrimoniales que se derivan de un vínculo entre personas del mismo sexo, pero la Corte fue más allá" (énfasis añadido). ${ }^{50}$

A primera vista, el argumento citado parecería ser persuasivo; no obstante, a través de un análisis integral de los fallos dictados por la Corte IDH, es posible afirmar que la Corte Provincial, sin respaldo jurídico alguno, concluye que aquella excedió sus prerrogativas. Dicha afirmación no es correcta, pues, si bien la facultad consultiva

47. Ecuador Corte Provincial de Justicia de Azuay Sala Penal, “Sentencia”, en Juicio n. ${ }^{\circ}$ 01204-2018-03637, 10 de septiembre de 2018.

48. Ecuador, Constitución de la República del Ecuador, Registro Oficial 449, 20 de octubre de 2008, art. 67.

49. Ecuador, Ley Orgánica de Gestión de la Identidad y Datos Civiles, Registro Oficial 684, 5 de julio de 2018, art. 52. Ecuador, Código Civil, Registro Oficial Suplemento 46, 24 de junio de 2005, arts. 81-104.

50. Ecuador Corte Provincial de Justicia de Azuay Sala Penal, "Sentencia", en Juicio n. ${ }^{\circ}$ 01204-2018-03637, 10 de septiembre de 2018. 
-regulada en el artículo 64.1 de la CADH- surge a petición de parte, ${ }^{51}$ la Corte está autorizada incluso para reformular las preguntas que se le planteen.

Aterrizando en el caso de estudio, la Corte IDH ha mencionado que "por la forma en que ha sido redactada una solicitud, [puede] en el ejercicio de sus funciones [... ] tener que precisar o esclarecer, y en ciertos supuestos, reformular, las preguntas que se le plantean, con el fin de determinar con claridad lo que se le está preguntando" (énfasis añadido). ${ }^{52}$ Lo anterior implica que la Corte IDH tiene la facultad de reformular y esclarecer preguntas porque aquello es, precisamente, su labor como intérprete oficial de la $\mathrm{CADH}$ a la hora de responder una consulta con estructura lógica y de manera que se adecue a los intereses de la justicia y a los efectos de una Opinión Consultiva.

De igual manera, la Corte IDH ha reconocido en sus múltiples pronunciamientos cuáles son las facultades que le corresponden dentro de su función consultiva. Así, en resolución de 14 de abril de 1997, sostuvo que puede mantener el conocimiento de un trámite de Opinión Consultiva incluso si el Estado solicitante retira la solicitud. ${ }^{53}$ Asimismo, ha señalado que puede reordenar las preguntas presentadas para clarificar su pronunciamiento. ${ }^{54}$

Por lo expuesto, "la Corte debe trabajar cómodamente, no solo en cuanto a los medios humanos y materiales sino también en su posibilidad de reposar en la amplia capacidad de conducir y ordenar un proceso que tenga a su cargo, ya sea en materia contenciosa o consultiva". ${ }^{55} \mathrm{Al}$ ser la Corte IDH un órgano que reconoce, tutela y garantiza derechos humanos por la confianza que los Estados han depositado en ella para llevar a cabo sus tareas, los Estados no deberían temer de las amplias facultades que goza a la hora de intervenir como intérprete en el legítimo ejercicio de sus funciones $y$, en aplicación del principio iura novit curia, ir más allá de lo solicitado por las partes.

51. Convención Americana de Derechos Humanos, 1969, art. 64.

52. Corte IDH, "Opinión Consultiva OC-7/86 sobre exigibilidad del derecho de rectificación o respuesta", 29 de agosto de 1986, párr. 12.

53. Corte IDH, "Resolución del 14 de abril de 1997 en el marco del trámite de la Opinión Consultiva OC-15/97 de 14 de noviembre de 1997'. Informes de la Comisión Interamericana de Derechos Humanos, párr. 58.

54. Vid., Corte IDH, "Opinión Consultiva OC-7/86 sobre exigibilidad del derecho de rectificación o respuesta”, 29 de agosto de 1986, párr. 12.

55. Fabián Salvioli, "La competencia consultiva de la Corte Interamericana de Derechos Humanos: marco legal y desarrollo jurisprudencial", en Homenaje y reconocimiento a Antônio Cançado Trindade, editado por Sergio Fabris, tomo III (Brasilia, 2004), 417-72. 


\section{CONCLUSIONES}

A lo largo de este trabajo investigativo se ha reforzado la obligatoriedad de las Opiniones Consultivas de la Corte IDH como instrumentos vinculantes para los Estados parte de la CADH. Si bien este debate se encuentra en auge en la región latinoamericana, en Ecuador la Constitución y su máximo intérprete reconocen que estos instrumentos prevalecen sobre la Norma Suprema cuando en ellos se contienen derechos más favorables. Asimismo, el bloque de constitucionalidad incorpora estos instrumentos en el ordenamiento jurídico ecuatoriano, otorgándoles directa aplicabilidad a fin de proteger la dignidad humana.

En consecuencia, la determinación de qué instrumento debe aplicarse a un caso concreto pende, en última instancia, de un análisis respecto de la favorabilidad con que se protege el goce y ejercicio de los derechos, el cual no puede realizarse de manera somera y, al contrario, deberá incorporar una motivación explícita. Es preocupante que en las sentencias de la Corte Provincial referidas los jueces no hayan realizado análisis alguno en este sentido, considerando que la administración de justicia constitucional es una tarea que corresponde a todos los juzgadores.

Así, al ser la OC-24/17 un instrumento que garantiza la plena vigencia de varios derechos, entre ellos la igualdad y no discriminación, y el derecho a la familia, de manera más favorable que la propia Constitución, esta debió ser aplicada por sobre la norma suprema. Su falta de aplicación no solo vulneró las disposiciones constitucionales que le otorgan una jerarquía superior, pero además comprometió la responsabilidad estatal del Estado ecuatoriano, ya que sus funcionarios violaron su deber más elemental, el garantizar de manera irrestricta a toda persona el ejercicio más amplio y favorable de derechos, haciendo realidad el mandato constitucional.

\section{BIBLIOGRAFÍA}

Convención Americana sobre Derechos Humanos. 1969.

Convención de Viena sobre el Derecho de los Tratados. 1969.

Convenio Europeo Convenio para la Protección de los Derechos Humanos y de las Libertades Fundamentales. 1990.

Corte IDH. "Opinión Consultiva OC-7/86 sobre exigibilidad del derecho de rectificación o respuesta". 29 de agosto de 1986.

- " "Opinión Consultiva OC-1/83 del 24 de septiembre de 1982 sobre 'otros tratados' objeto de la facultad consultiva de la Corte". 24 de septiembre de 1982.

—. "Opinión Consultiva OC-15/97 del 14 de noviembre de 1997 sobre informes de la Comisión Interamericana sobre Derechos Humanos". 14 de noviembre de 1997. 
—. "Opinión Consultiva OC-23/17 del 15 de noviembre de 2017 sobre medioambiente y derechos humanos". 15 de noviembre de 2017.

—. "Opinión Consultiva OC-24/17 del 24 de noviembre de 2017 sobre identidad de género, e igualdad y no discriminación a parejas del mismo sexo”. 24 de noviembre de 2017.

—. "Opinión Consultiva OC-3/83 del 8 de septiembre de 1983 sobre las restricciones a la pena de muerte". 8 de septiembre de 1983 .

—. "Resolución del 14 de abril de 1997 en el marco del trámite de la Opinión Consultiva OC15/97 de 14 de noviembre de 1997". Informes de la Comisión Interamericana de Derechos Humanos.

-. "Opinión Consultiva 1/82 del 24 de septiembre de 1982 'otros tratados' objeto de la función consultiva de la Corte". 24 de septiembre de 1982.

—. “'Opinión Consultiva OC-6/86 sobre la expresión 'leyes' en el artículo 30 de la Convención Americana de Derechos Humanos”. 9 de mayo de 1986.

Corte Internacional de Justicia. "Fallo de 13 de diciembre de 1999, Caso relativo a la isla Kasikili/Sedudu entre Botswana y Namibia. 13 de diciembre de 1999. 〈https://www.dipublico. org/cij/doc/127.pdf).

—. "Fallo de 27 de junio de 2001". Caso relativo a LaGrand. 27 de junio de 2001.

—. "Fallo de 3 de febrero de 1994", Caso relativo a la controversia territorial Jamahiriya Árabe Libia/Chad. 3 de febrero de 1994. 〈https://www.dipublico.org/cij/doc/97.pdf〉.

Diez de Velasco, Manuel. Instituciones de Derecho Internacional Público. Madrid: Tecnos, 2002.

Ecuador. Corte Constitucional. "Resolución 9", Registro Oficial 597, 15 de diciembre de 2011.

—. "Sentencia". En Juicio n. ${ }^{\circ}$ 026-12-SIS-CC. 21 de junio de 2012.

—. "Sentencia". En Juicio n. ${ }^{\circ}$ 004-14-SCN-CC. 6 de agosto de 2014.

—. "Sentencia". En Juicio n. ${ }^{\circ}$ 003-14-SIN-CC. 17 de septiembre de 2014.

—. "Sentencia". En Juicio n. ${ }^{\circ}$ 064-15-SEP-CC. 11 de marzo de 2015.

—. "Sentencia". En Juicio n. 019-16-SIN-CC. 22 de marzo de 2016.

—. "Sentencia". En Juicio n. ${ }^{\circ}$ 184-18-SEP-CC. 29 de mayo de 2018.

Ecuador Corte Provincial de Justicia de Azuay Sala Laboral. "Sentencia”. En Juicio n. ${ }^{\circ} 01204-$ 2018-03635. 10 de septiembre de 2018.

Ecuador Corte Provincial de Justicia de Azuay Sala Penal. "Sentencia”. En Juicio n. ${ }^{\circ} 01204$ 2018-03637. 10 de septiembre de 2018.

Ecuador Corte Provincial de Justicia de Pichincha Sala Civil y Mercantil. "Sentencia". En Juicio $n .^{\circ} 17159-2018-00006.16$ de octubre de 2018.

Ecuador Unidad Judicial de Familia Mujer, Niñez y Adolescencia. "Sentencia". En Juicio n. ${ }^{o}$ 01204-20180-3635. 16 de julio de 2018.

Ecuador. Constitución de la República del Ecuador. Registro Oficial 449, 20 de octubre de 2008. 
-. Ley de Garantías Jurisdiccionales y Control Constitucional. Registro Oficial 52, 22 de octubre de 2009.

—. Ley Orgánica de Gestión de la Identidad y Datos Civiles. Registro Oficial 684, 5 de julio de 2018.

-. Código Civil. Registro Oficial Suplemento 46, 24 de junio de 2005.

Faúndez Ledesma, Héctor. El sistema interamericano de protección de los derechos humanos: aspectos institucionales y procesales. 2. ' ed. Costa Rica: Editorial IIDH, 1999.

Hitters, Juan Carlos, y Óscar Fappiano. Derecho Internacional de los Derechos Humanos. Buenos Aires: Ediar, 1999.

Nieto-Navia, Rafael. "El valor jurídico de las recomendaciones de los Comités de Derechos Humanos y el bloque de constitucionalidad". 18 International Law. Revista Colombiana de Derecho Internacional, 155, n. ${ }^{\circ} 190$ (2011).

Nikken, Pedro. "La función consultiva de la Corte Interamericana de Derechos Humanos". Instituto de Investigaciones Jurídicas de la Universidad nacional Autónoma de México 15 (1999). 〈https://archivos.juridicas.unam.mx/www/bjv/libros/5/2454/10.pdf〉.

Salvioli, Fabián. "La competencia consultiva de la Corte Interamericana de Derechos Humanos: marco legal y desarrollo jurisprudencial". En Homenaje y reconocimiento a Antônio Cançado Trindade, editado por Sergio Fabris. Tomo III. Brasilia, 2004. 